\title{
sciendo DESIGN AND MODELING OF AN EXPERIMENTAL HYDRAULIC DEVICE
}

doi:10.2478/mape-2018-0009

Date of submission of the article to the Editor: 04/2018

Date of acceptance of the article by the Editor: 07/2018
MAPE 2018, volume 1, issue 1, pp. 63-68

\author{
Prof. Ing. Zdenko Tkáč, PhD. \\ Ing. Marek Halenár \\ Ing. Ján Kosiba, PhD. \\ Slovak University of Agriculture in Nitra, Slovak Republic
}

\begin{abstract}
The design of the experimental laboratory device is based on the construction of the hydraulic circuits of mobile devices. It is possible to ensure the repeatability of the flow characteristic measurements at the laboratory. This means that in the operating test it is possible to verify the flow characteristics of the hydraulic pump and these results are not affected by the change in the physical properties of the applied liquid. By comparing of the flow characteristics directly on the work equipment (mini-excavator, etc.), the disadvantage is the need for dismantling the hydraulic pump and its mounting on the laboratory device. In some working device removal is not possible, where dismantling is structurally difficult or is time consuming, which increases the cost of their operation. The proposed experimental laboratory device serves to verify the flow characteristics of the hydraulic pump and is also designed to be universal, to test external gear hydraulic pump and hydraulic pump with inclined plate.
\end{abstract}

Keywords: hydraulic fluid, flow rate, flow rate efficiency

\section{INTRODUCTION}

Hydraulic device is widely used in powerful mechanisms of agricultural and forest machines as well as in many other areas. The development of modern hydraulic components is aimed at increasing the transmitted power, reducing the energy intensity, minimizing the environmental pollution and increasing the technical life and machine reliability (Tóth et al., 2014, Kučera et al., 2016a). Hydraulic circuit components and hydraulic fluid must meet all the requirements of operating a hydraulic system. Because of this, they use accelerated hydraulic components and fluids testing in laboratory conditions to simulate operational conditions, usually specified by a standard (Kučera et al., 2016b, Tulík et al., 2013)). Today's technology of high performance hydraulic power systems is closely connected with the high development level of hydraulic fluids. (Kučera et al., 2013). A good hydraulic fluid should have the following characteristics: power transmission with a minimum loss, lubrication of surfaces moving against each other and corrosion protection of metal surfaces (Mendoza et al., 2011).

\section{DESIGN OF EXPERIMENTAL HYDRAULIC DEVICE}

The determination of the individual components of the hydraulic device to assess the operation of the hydraulic pumps is based on the relations between authors Baroška (2012), Will et al. (2011), Lindák et al. (2014) and Sigloch (2009). Inner surface:

$$
d_{p}=\sqrt{\frac{4 . Q}{\pi \cdot w}}
$$

where:

$Q$ - flow rate, $\mathrm{dm}^{3}$. .rpm

$w$ - resistance to flow rate, $\mathrm{m} . \mathrm{s}^{-1}$

Wall thickness of a pipe: 


$$
s=\frac{p_{\max } \cdot d_{p}}{2 \cdot \delta} \cdot k
$$

where:

$p_{\max }-$ max. pressure, $\mathrm{MPa}$

$d_{p}$ - inner surface, $\mathrm{m}^{2}$

$\delta$ - ultimate tensile strength, $\mathrm{Pa}$

Specific cooling power:

where:

$$
P_{01}=\frac{P_{V}}{T_{1}-T_{2}}
$$

$P_{v}$ - cooling power, $\mathrm{W}$

$T_{1}$ - max. temperature, ${ }^{\circ} \mathrm{C}$

$\mathrm{T}_{2}-$ min. temperature, ${ }^{\circ} \mathrm{C}$

Cooling power:

$$
P_{0}=P_{01} \cdot 1.1
$$

To determine the basic parameters of an experimental laboratory device, the calculations were used:

- inner surface (min.) $-9.86 \mathrm{~mm}^{2}$,

- wall thickness of a pipe (min.) $-1.21 \mathrm{~mm}$,

- specific cooling power (min.) $-0.1165 \mathrm{~kW} .{ }^{\circ} \mathrm{C}^{-1}$,

- cooling power (min.) $-0.1215 \mathrm{~kW} .{ }^{\circ} \mathrm{C}^{-1}$.

Based on the catalog data, a pipeline of diameter $d=14 \mathrm{~mm}$, with wall thickness $\mathrm{s}=1.5 \mathrm{~mm}$ and tank with capacity $\mathrm{V}=80 \mathrm{dm}^{3}$ were selected. The cooler is used for cooling EMMEGI type $2024 \mathrm{~K} 230-400$ with cooling power $\mathrm{P}_{0}=0.2 \mathrm{~kW} .{ }^{\circ} \mathrm{C}^{-1}$.

The construction is based on the universality of the proposed experimental laboratory equipment. The hydraulic device (Fig. 1) is designed with two separate hydraulic circuits. One is used to test regulating hydraulic pump with a tilting plate and the other for toothed hydraulic pumps with external gearing. Both of these circuits have their own tank, cooling and filter circuit.

Hydraulic circuit B serves to verify the flow characteristics of the toothed hydraulic pump with external gearing. There is a pressure valve in the circuit $\left(\mathrm{PV}_{2}\right)$ in the safety valve function, after the pressure has been exceeded $p=20 \mathrm{MPa}$, the liquid is returned to the tank $\left(\mathrm{N}_{2}\right)$.

Flow sensor is used to verify flow characteristics (Q2). We can use mechanical throttle valve on the load on the hydraulic pump (HP) or proportional throttling valve (PTV). The three-way valve (TwV) serves to link the selected load method. By using the mechanical throttle valve, the pressure is increased by changing the flow rate (by gradually pulling the compression spring). When using the proportional throttle valve (PTV), the process of changing the flow rate is controlled by the solenoid. A second alternative to verifying flow characteristics of toothed hydraulic pump with external gearing in the hydraulic circuit $B$ is the use of the volumetric flow meter $(\mathrm{Q})$. Flow control via bulk flow meter is controlled through a two-position hydraulic valve $(\mathrm{HV})$. Using a digital trigger, the two-position switchgear switches to a liquid flow through a volume flow meter $t=60 \mathrm{~s}$. On the basis of the above data, the flow characteristic (liquid flow) of the hydraulic pump is given. The possibility of verifying the flow characteristics of the toothed hydraulic pump is possible with the use of the reducing valve $(\mathrm{RV})$ and proportional throttle valve (PTV). A filter (F2) with filter inserts and a cooler (C2) is connected to the output line. The cooler maintains a constant temperature $t=40^{\circ} \mathrm{C}$ when measuring flow characteristics. Mechanical thermostats are used to switch coolers. For temperature monitoring in hydraulic circuits, dilatation thermometers (t) are located in tanks. Thermal sensors ( $\mathrm{t} 1$ and $\mathrm{t} 2$ ) are used to determine accurate temperature data. To measure of the pressure in the hydraulic circuits are used in pressure gauges $(P)$, respectively pressure sensors ( $p 1$ and $p 2)$. An inductive speed sensor ( $n$ ) is used to monitor the speed on the 
mechanical coupling (MC). A digital recording (HMG 3010) unit is used to record the measured flow (sensors Q1 and Q2), the temperature (sensors t1 and t2), and the pressure values (sensors $\mathrm{p} 1$ and $\mathrm{p} 2$ ). As a result of the rolling of the gear, there is a timing change in the values of flow and pressure of liquid.

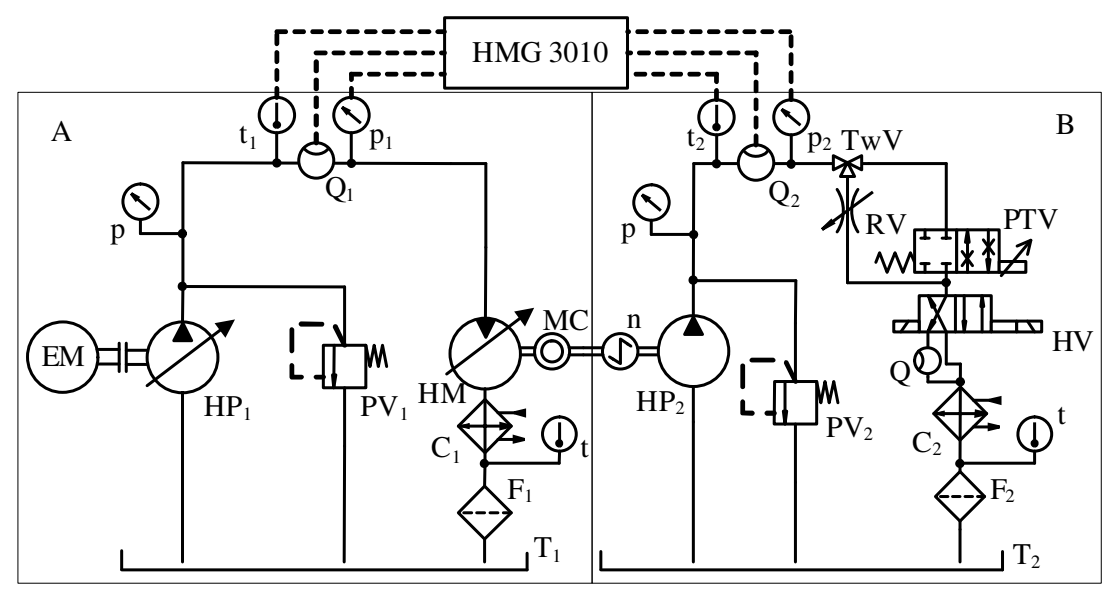

Fig. 1. Kinematic scheme of hydraulic circuit

(A - primary circuit, B - secondary circuit, EM - electromotor, $\mathrm{HP}_{1}$ - regulatory hydraulic pump,

$\mathrm{PV}_{1}, \mathrm{PV}_{2}$ - pressure valve, $\mathrm{p}$ - manometer, $\mathrm{t}_{1}, \mathrm{t}_{2}$ - temperature sensor ETS 4148-H-006-000,

$Q_{1}, Q_{2}$ - flow sensor EVS 3108-H-0300-000, $p_{1}, p_{2}$ - pressure sensor HDA 4748-H-0400-000,

$Q$ - volume flowmeter, $\mathrm{t}$ - temperature gauge, $\mathrm{HM}$ - regulatory hydromotor, $\mathrm{HP}_{2}$ - gear hydraulic pump, RV - reducing valve, HV - hydraulic valve, PTV - proportional throttle valve,

TwV - three-way valve, MC - mechanical coupling, $n$ - rpm sensor ISP 308 S 01 N, $F_{1}, F_{2}$ - filter, $\left.T_{1}, T_{2}-\operatorname{tank}\right)$

\section{RESULTS AND DISCUSSION}

The design of an experimental laboratory hydraulic device has taken into account its versatility. It consists of two separate circuits. The throttle valve (TrV), respectively the proportional throttling valve (PTV) is used for the load. The possibility of selecting the method of filling the hydraulic pumps provides a three-way valve (TwV). Thrust valve loads have been used by their authors Inaguma and Yoshida (2013) and Rana (2015) in their laboratory hydraulic devices. The proportional throttling valve were used by the authors Kim and Kim (2013) a Kozuma et al. (2005) for load in their work.

The method for the verification measurement of the hydraulic pump, which is tested by the laboratory testing device, comprises of estimating a relation between the flow of the hydraulic pump and its speeds. Verification measurements were made at $1,500 \mathrm{rpm}$ speeds of the hydraulic pump. The verification measurement results are shown in Figs. 2 and 3.

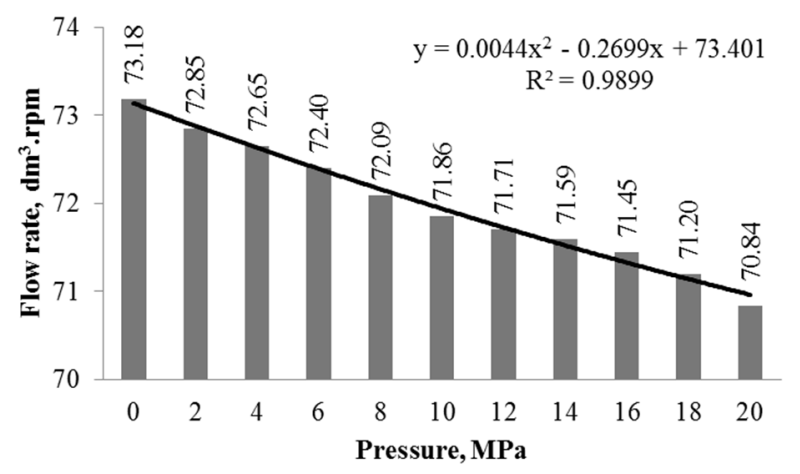

Fig. 2. Flow rate of the regulating hydraulic pump 


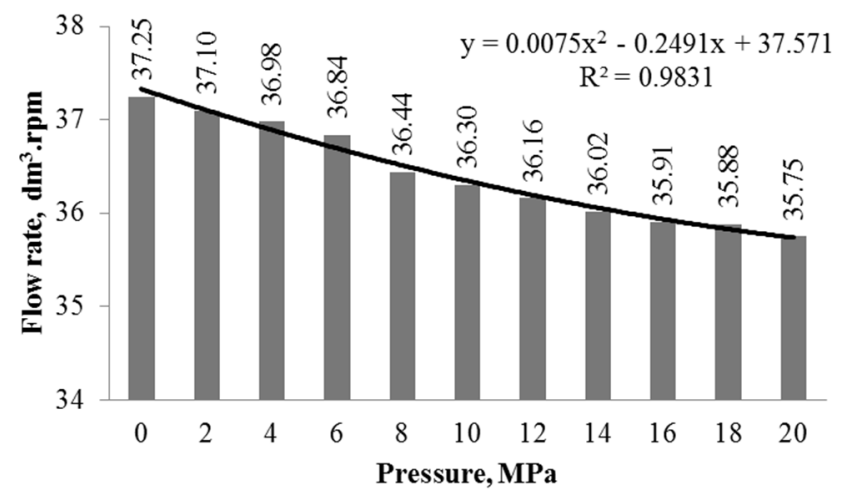

Fig. 3. Flow rate of the gear hydraulic pump

Flow efficiency of hydraulic pump (Fig. 4 and 5) will be calculated form the measured flow characteristic:

$$
\eta_{p}=\frac{Q}{V_{G} \cdot n} \cdot 100
$$

where:

$Q$ - hydraulic pump flow, $\mathrm{dm}^{3}$.rpm

$V_{G}-$ geometrical volume of hydraulic pump, $\mathrm{dm}^{3}$

$n$ - nominal speed of hydraulic pump, 1.rpm

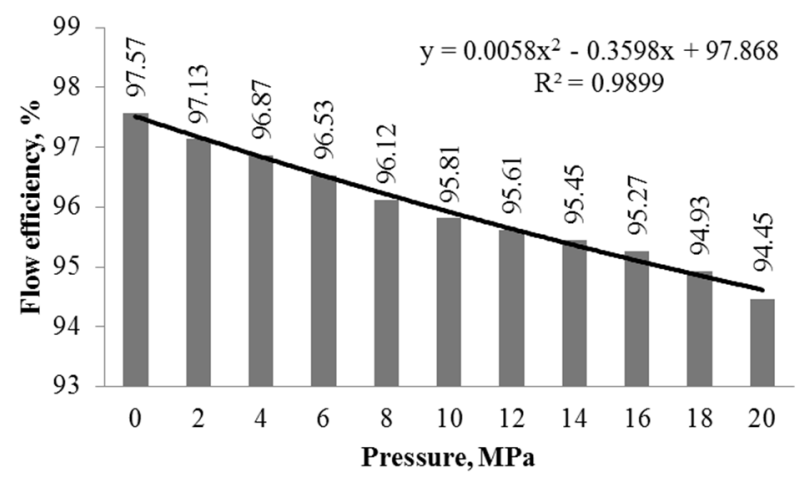

Fig. 4. Flow efficiency of the regulating hydraulic pump

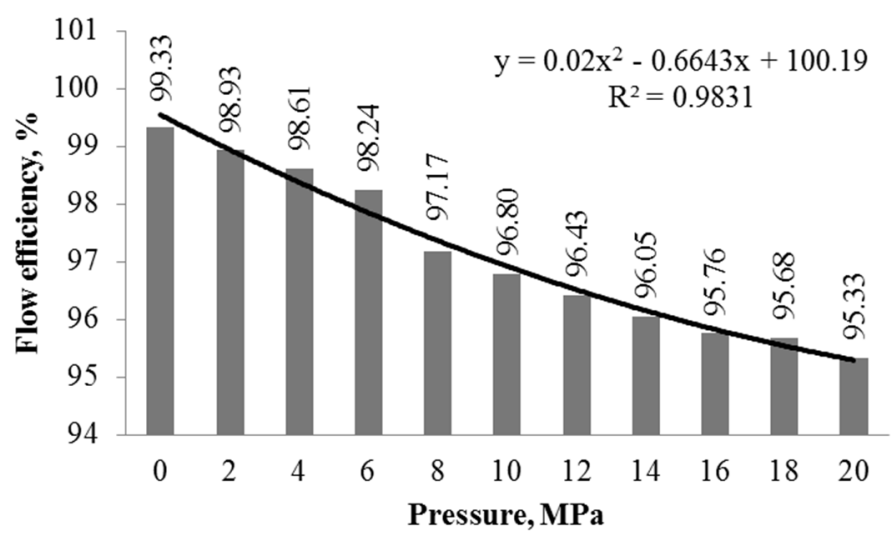

Fig. 5. Flow efficiency of the gear hydraulic pump

During the verification of the operation of the hydraulic circuit, the characteristics of the flow and thus the efficiency of the hydraulic pump flow were verified. In the gear hydraulic pump, 
under pressure $p=0 \mathrm{MPa}$ and speed $n=1,500 \mathrm{rpm}$, the flow efficiency of the value was determined $\eta_{p p}=99.33 \%$ and under pressure $p=20 \mathrm{MPa}$, value $\eta_{p p}=95.33 \%$. In the regulating hydraulic pump, under pressure $\mathrm{p}=0 \mathrm{MPa}$ and speed $1,500 \mathrm{rpm}$, the flow efficiency of the value was determined $\eta_{p p}=97.57 \%$ and under pressure $p=20 \mathrm{MPa}$, value $\eta_{p p}=94.45 \%$. The decrease in flow rate of the hydraulic pump in relation to the pressure corresponds to the results of the operating tests and to the results published in the work of the authors Dobrota et al. (2010) (for the gear pump) and data from Dynatec (2011) for the regulating hydraulic pump.

On the basis of the theoretical processing of the authors Hao et al. (2016), Chrastina et al. (2013) and Casoli et al. (2005), it is possible to determine the coefficient of loss of liquid $k_{Q}$, which affects the resulting liquid flow.

Displacement gear pumps:

$$
q=2 \cdot z_{m}\left(V_{1}-V_{\text {loss }}\right)=2 \cdot z_{m}\left[\frac{n}{360} \pi \cdot r_{a 1}^{2}-\int f\left(x_{0}, y_{0}\right) d x-V_{s t r}\right]
$$

where:

$z_{m}$ - number of tooth gaps,

$V_{1}-$ volume of tooth gap, $\mathrm{m}^{3}$

$n-$ speed, $\mathrm{s}^{-1}$

$V_{\text {loss }}$ - loss volume, $\mathrm{m}^{3}$

$r_{a 1}$ - radius of the gearhead, $m$

Loss volume:

$$
V_{s t r}=\int_{x_{j 1}}^{x_{j 2}}\left[f\left(x_{2}, y_{2}\right)-f\left(x_{1}, y_{1}\right) d x\right]
$$

where:

$f\left(x_{2}, y_{2}\right)$ a $f\left(x_{1}, y_{1}\right)$ - gear rotation function

The average value of the time change of the fluid flow can be determined based on:

$$
\bar{Q}=\frac{\omega}{2 \cdot \pi} \cdot q
$$

where:

$\omega$ - angular velocity, rad. $\mathrm{s}^{-1}$

Resulting Loss Flow Ratio:

$$
k_{Q}=\frac{Q_{\max }-Q_{\min }}{\bar{Q}}
$$

where:

$Q_{\max }-$ maximum flow of fluid, $\mathrm{m}^{3} \cdot \mathrm{s}^{-1}$

$Q_{\min }-$ minimum flow of fluid, $\mathrm{m}^{3} \cdot \mathrm{s}^{-1}$

\section{CONCLUSION}

Farm machinery manufacturers have recently tried to introduce into hydraulic systems new plant- or synthetic-based fluids and oils that are more environmentally friendly, decomposable and less damaging to water resources (Molari and Sedoni, 2008). The main requirement of the laboratory testing device was to simulate a real hydraulic circuit of a farm tractor as closely as possible. That is why the hydraulic circuit components, cyclical load application and fluid temperature were selected based on technical and operational data of farm machinery and its real-life use (Tkáč et al., 2018). Machinery manufacturers have recently tried to introduce into hydraulic systems new plant- or synthetic-based fluids and oils that are more environmentally friendly, decomposable and less damaging to water resources. In the gear hydraulic pump, under pressure $p=0 \mathrm{MPa}$ and speed $n=1,500 \mathrm{rpm}$, the flow efficiency of the value was determined $\eta_{p p}=99.33 \%$ and under pressure $p=20 \mathrm{MPa}$, value $\eta_{p p}=95.33 \%$. In the regulating hydraulic pump, under pressure $p=0 \mathrm{MPa}$ and speed $1,500 \mathrm{rpm}$, the flow efficiency of the value was determined $\eta_{p p}=97.57 \%$ and under pressure $p=20 \mathrm{MPa}$, value $\eta_{p p}=94.45 \%$. 


\section{ACKNOWLEDGEMENT}

Supported by the Ministry of Education of the Slovak Republic, Project VEGA 1/0155/18.

\section{REFERENCES}

Asaff, Y., De Negri, V.J., Theissen, H. and Murrenhoff, H. (2014). Analysis of the Influence of Contaminants on the Biodegradability Characteristics and Ageing of Biodegradable Hydraulic Fluids. Strojniski Vestnik - Journal of Mechanical Engineering, 60(6). pp. 417-424.

Casoli, P., Vacca, A. and Franzoni, G. (2005). A Numerical Model for the Simulation of External Gear Pumps. JFPS Symposium on Fluid Power, TSUKUBA, pp. 705-710.

Dobrota, D., Lalic, B. and Oršulić, M. (2010). Experimental Modielng of Volumetric Efficiency of High Pressure External Gear Pump. Naše More, 57(5-6), pp. 235-240.

Dynatec. 2011. Hydraulic components. Taichuna City, Taiwan.

Hao, X., Zhou, X., Liu, X. and Sang, X. (2016). Flow characteristics of external gear pumps considering trapped volume. Advances in Mechanical Engineering, 8(10), pp. 1-10.

Chrastina, J., Janoško, I. and Polonec, T. (2013). System for monitoring operating parameters of vehicles. Trends in agricultural engineering 2013. Prague: Czech University of Life Sciences Prague, pp. 267-272.

Inaguma, Y. and Yoshida, N. (2013). Mathematical analysis of influence of oil temperature on efficiencies in hydraulic pumps for automatic transmission. SAE International Journal of Passenger Cars Mechanical Systems, 6(2), pp. 786-797.

Kim, J.H. and Kim, S.G. (2013). A Study on the Approximate Model of the Flow Rate Characteristics in External Gear Pump for EHPS. Journal of the Korea Academia-Industrial cooperation Society, 14(2), pp. 548-553.

Kučera, M., Majdan, R., Abrahám, R., Kučera, M. and Haas, P. (2016). Analysis of the effect of loading process on tribological system properties. Acta Universitatis Agriculturae et Silviculturae Mendelianae Brunensis. 64(3), pp. 825833.

Kučera, M., Rusnák, J., Kadnár, M. and Malý, V. (2016). Analysis of tribologic properties of selected steels. Tehnički vjesnik, 23(3), pp. 647-651.

Kučera, M., Aleš, Z., Ivandić, Z. and Hujo L'. (2013). Possibility of hydraulic fluids with a low environmental impact application in agriculture and transport machinery. Journal of Central European Agriculture, 14(4), pp. 1575-1584.

Kozuma, F., Arita, T. and Tsuda, H. (2005). Development of Energy Saving Power Steering. JFPS Symposium on Fluid Power, TSUKUBA, pp. 297-300.

Lindák, S., Majdan, R., Janoško, I., Pap, M. and Szabó, M. (2014). Hydraulic device for simulation of pressure shocks. Acta technologica agriculturae. 17(2), pp. 44-48

Mendoza, G., Igartua, A., Fernandez-Diaz, B., Urquiola, F., Vivanco, S. and Arguizoniz, R. (2011). Vegetable oils as hydraulic fluids for agricultural applications. Grasas y aceites, 62(1), pp. 29-38.

Molari, G. and Sedoni, E. (2008). Experimental evaluation of power losses in a power-shift agricultural tractor transmission. Biosystems Engineering, 100(2) pp. 177-183.

Rana, A.D. (2015). Performance evaluation of external gear pump with the used of burnt oil. International Journal of Advanced Technology in Engineering and Science, 3(Special Issue), pp. 466-473.

Sigloch, H. (2009). Technische Fluidmechanik. Berlín: Springer-Verlag 2009.

Tkáč, Z., Kosiba, J., Hujo, L'., Jablonický, J. and Nosian, J. (2018). Experimental hydraulic device for the testing of hydraulic pumps and liquids. Tribology in Industry, 40(1). pp. 149-155.

Tóth, F., Rusnák, J., Kadnár, M. and Váliková, V. (2014). Study of tribological properties of chosen types of environmentally friendly oils in combined friction conditions. Journal of Central European Agriculture, 15(1) pp. 185-192.

Tulík, J., Hujo, L'., Stančík, B. and Sevčík, P. (2013). Research of new ecological synthetic oil-based fluid. Journal of Central European Agriculture, 14(4), pp. 1384-1393.

Will, D., Gebhardt, N., Nollau, R. and Herscher, D. (2011). Hydraulik. Heidelberg: Springer-Verlag. 